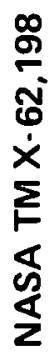

A STUDY ON AIRCRAFT MAP DISPLAY LOCATION AND ORIENTATION

D. Baty, T. Wempe and E. Huff

Ames Research Center

Moffett Field, Calif. 94035
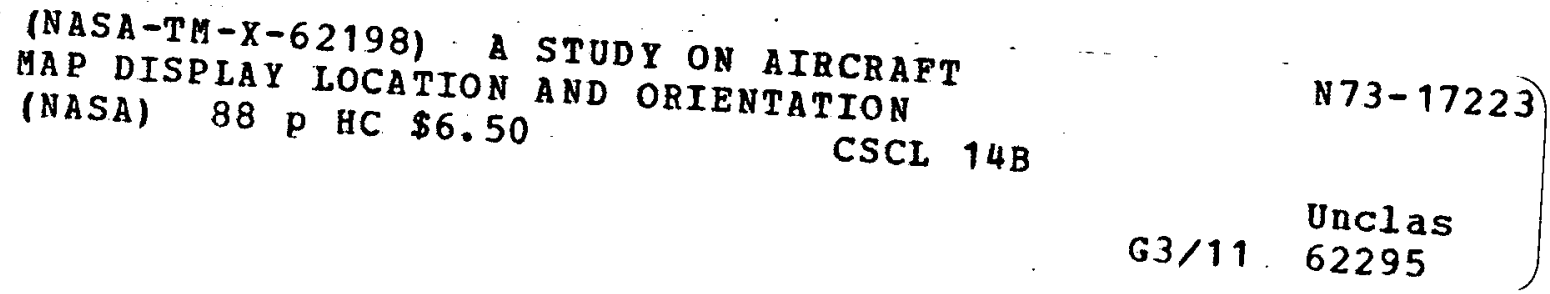

January 1973

semosenat as

NATIONAL TECHNICAL

INFORMATION SERYICE

US Department of Commerce

Springliold, VA. 2215i 


\title{
A STUDY ON AIRCRAFT MAP DISPLAY LOCATION AND ORIENTATION
}

D. L. Baty, T. E. Wempe \& E. M. Huff

\begin{abstract}
Six airline pilots participated in a fixed-base simulator study to determine the effects of two Horizontal Situation Display (HSD/map) panel locations relative to the Vertical Situation Display (VSD), and of three map orientations on manual piloting performance. Pilot comments and opinions were formally obtained. Significant performance differences were found between wind conditions and among pilots but not between map locations and orientations. The results also illustrate the potential tracking accuracy of such a display. Recommendations concerning display location and map orientation are made.
\end{abstract}




\section{INTRODUCTION}

Many advanced aircraft display designs include the use of cathode ray tubes (CRT) to present attitude information on a Vertical Situation Display (VSD) and navigation information on a Horizontal Situation Display (HSD). Due to the size of these tubes and mounting structures, there is often some restriction on their placement in the alrcraft panel, which in some cases may require that they be positioned side-by-side (most pilots seem a priori to prefer over-under placement).

A simulator study was conducted to investigate the effect of the relative position of these two displays on manual performance and included, as the other major variable, three (3) variations in HSD map orientation to test for interactions. Although there have been studies using projected map and CRT displays, e.g., (1)-(3), no comparative studies on location or orientation have been done. The results of this experiment which deal specifically with different map display locations and orientations should be applicable not only to CRT map displays but also to two other major types of map displays, namely, film projection and rear projection CRTs.

The simulator plloting task consisted of making a serfes of right and left procedure turns in level flight both in the presence and absence of cross winds. Pilot performance was measured by computing both lateral and vertical RMS errors. At the end of the experiment each pilot completed a detailed questionnaire about the experiment. The results of both the pilot performance data and the questionnaire data are presented and discussed. 


\section{$-r^{-}$}

TASK AND PROCEDURES

Task and Displays

The task was to fly from point A to point B, as in Fig. 1, following the $360^{\circ}, 315^{\circ}, 135^{\circ}, 180^{\circ}, 225^{\circ}, 045^{\circ}$ and $360^{\circ}$ legs in that sequence while maintaining constant altitude. The aircraft dynamics were a simplified version of the DC-8. Throttle setting remained constant with a nominal airspeed of 160 knots. All flight information was displayed on a 17 in. CRT monitor. The display was generated by an Evans \& Sutherland LDS-2 graphics display computer using an SEL 840 as the main computer. Aircraft dynamics and scoring procedures were also generated by the SEL 840. Approprlate force-feel characteristics were provided by a hydraulic control loader system. Fig. 2 is a photograph of the simulator interior.

Both the Vertical Situation Display (VSD) and the Horizontal Situation Display (HSD) were contained within 5 in. squares. Fig. 3 is a photograph of the VSD with labels describing the display elements. The number at the top left corner of the display shows airspeed in knots. The center number is aircraft heading in degrees. The top right number is altitude in feet, and the number just below altitude is the vertical speed readout in feet per minute. The aircraft aymbol remained fixed in the center of the display with pitch and roll indicated by movement of the horizon, ground plane lines and pitch lines. The altitude error bar moved across the scope in the vertical direction only. A zero altitude error was indicated when the error bar was centered over the center square of the aircraft symbol. Motion from the center position to the end of the bar in either direction indicated a 
$100 \mathrm{ft}$. error. The alrcraft was $100 \mathrm{ft}$. too high when the top end of the bar was just touching the square, 1.e., the bar below the aircraft symbol, and $100 \mathrm{ft}$. too low when the bottom end of the bar was touching the square. The rectangle of the turn rate indicator moved horizontally. Center position indicated zero turn rate and a $3 \% \mathrm{sec}$. turn was indicated with the rectangle centered over the right or left bar.

Figure 4 is a photograph of the HSD with labels describing the display elements. The primary display elements were the reference ground trajectory and the aircraft symbol. The aircraft symbol gave both headIng and position information. The aircraft position was the junction point of the wings and body. The other symbols were present to provide a touch of realism and to provide background display motion which was considered particularly important for the two conditions where the aircraft remained in the center of the display during the flight. For these two conditions the map translated and additional symbols, not shown here, would come into view at different points along the flight. The map scale is $1.6 \mathrm{n}$. mi./in.

One additional feature was shown on both the VSD and HSD to aid in timing the start of the turns. Approximately 5 seconds before the transition point from a straight line section of the reference ground trajectory to a circular section, the center square of the VSD aircraft symbol and the aircraft symbol on the HSD both began to flash at a $2 \mathrm{~Hz}$ rate. Referring to Fig. 1 it can be seen that there are 2 turns of $180^{\circ}$ and 4 turns of $45^{\circ}$. For the $45^{\circ}$ turns the flashing began 5 seconds before the tangent point of a circle with the same radius as the $180^{\circ}$ turns. 
This is illustrated on Fig. 1 at the $045^{\circ}$ to $360^{\circ}$ heading transition. The VSD was always in the same scope location for either the overunder or the side-by-side condition. The VSD center-line was centered directly in front of the pilot. The map (HSD) was positioned either to the right of the VSD or below $1 t$.

\section{Experimental Variables}

Relative display location: Two levels, VSD and HSD located either over-under $\left(D_{2}\right)$ or side-by-side $\left(D_{1}\right)$.

Map orientation: Three levels were used.

1. North up, fixed map $\left(0_{1}\right)$. With this condition all elements were fixed, the only moving symbol being the aircraft which moved around the course to indicate present position and heading.

2. Aircraft heading up $\left(\mathrm{O}_{2}\right)$. The aircraft symbol always remained fixed in the center of the display, heading up. The entire map would translate and rotate to keep proper relative position with the aircraft.

3. North up, moving map $\left(\mathrm{O}_{3}\right)$. The center of the aircraft remained centered in the display and rotated about this center to indicate aircraft heading. The map always remained north-up (no rotation) and translated vertically and horizontally to maintain relative position with the aircraft. This configuration was chosen because it is a mix of inside-out and outside-in displays. The "north-up, fixed map" display is a pure outside-in display and the aircraft heading up display is a pure inside-out display. In this (3rd) display the aircraft position is inside-out, while the aircraft heading is outside-in. 
Figures 5, 6 and 7 are photographs showing a combination of the display locations and map orientations.

Winds: Two levels; wind present $\left(W_{1}\right)$ and wind absent $\left(W_{0}\right)$. When present the wind velocity was always 32 knots. Wind direction was randomly selected from four cholces, blowing from either $068^{\circ}, 143^{\circ}$, $223^{\circ}$ or $338^{\circ}$.

Pilot groups: Two groups selected on the basis of a pre-experiment questionnaire. The group of 3 pilots preferring the side-by-side placement of the display was designated Group A, and 3 pilots preferring the over-under placement was called Group B.

Pilots: Six airline pilots were chosen from a group of 19 pilots on the basis of their responses to a Display Location Preference questionnaire. Fig. 8 is a reproduction of the paired-comparison part of the questionnaire. This page was preceeded by explanatory material concerning CRT, VSD and map displays along with illustrations. The questionnaire also included a 5 point rating scale designed to determine the strength of their preference. (See Appendix A for further discussion.) The six airline pilots represented four airlines. One was a Captain and five were copllots, of which two were currently flying as second officers due to "bumping" procedures. The average age was 39 , average total flight time was 9,000 hrs., and all had military experience with an average total of $3,000 \mathrm{hrs}$. 


\section{Procedure}

Instructions: The purpose of the experiment, the details of the displays, the aircraft dynamics and the experimental conditions were all explained the first day. The stated task was, "stay as close to the reference ground trajectory as possible at all times while still maintaining altitude." They were instructed to set up approximately the same turn rate for the $45^{\circ}$ turns as for the $180^{\circ}$ turns, using the blinking of the aircraft symbols to aid in timing the beginning of the turns. They were informed of all the conditions before each run, including wind direction. They were instructed that "once we start a run for data, I want you to complete that run unless something unplanned happens, e.g., something obviously wrong with the simulation." They had a separate printed chart on a clipboard similar to Fig. 1, with headings and wind directions for handy reference.

At the end of each flight the pilot was shown the ground track of his entire flight path relative to the reference ground trajectory, as in Fig. 9. Also shown were the average mean square errors for both horizontal and vertical track (digits in upper left).

Performance measure: Average mean square errors (AMSE) for the total run were computed on-line for both horizontal and vertical errors. Training and experiment design: The combination of two display locations, three map orientations and two wind conditions made a total of twelve experimental conditions per pilot. Each pilot flew only one display orientation per day. With six pilots all possible sequence 
combinations were used as shown in Table 1 . These were also divided so that the three different orientations were present within preference groups for each day. Twelve recorded flights were made each day making three replications per map orientation for each of the four display 10cations (2) by wind conditions (2). These four conditions were randomized in blocks of four runs.

The first day was devoted entirely to training. Before collecting data on each of the following days two runs were made for warmup - one with and one without wind. The pilots were given the option of more warmup, but generally felt one run would have been sufficient. Each pilot averaged one or two sessions per week. Each run lasted approximately 6-1/2 minutes with about three minutes between runs. It was left to the individual pilot to take a longer break whenever he wished. The average break lasted about 20 minutes and was taken about halfway through the data runs. 
RESULTS AND DISCUSSION

This section is divided into two major parts. The first part presents the results of the pllot performance data, including a subsection dealing with an unexpected phenomenon that has been termed "fascination." The second part presents the results of the Post Experiment Questionnaire.

\section{Performance Data}

The magnitudes of the performance scores for each experimental variable are shown in Figs. $11-14$. The overall mean for each choice of a variable is designated by the diamond symbol. For Figs. 11 - 13, the range of individual pilot mean scores are also shown. Fig. 11 shows that lateral performance was slightly better with map orientation $0_{2}$, and vertical performance slightly better with orfentation $0_{1}$. These differences were not statistically significant. (See Tables III and IV for a statistical summary of results.) Figure 12 shows very little performance difference between the two display location cholces. with an average RMS lateral error slightly less than 100 meters, and an RMS vertical error slightly less than 8 meters.

The mean performance on wind conditions is shown in Fig. 13. These differences between wind conditions are statistically significant. The scores for each pilot are shown in Fig. 14. The differences shown among pilots are also statistically significant. The scores at the top of the dotted lines are the means for these runs with wind added, and those at the bottom are for runs without winds. 
It is clear that there was a difference in emphasis between the lateral and vertical task among pilots. P1lot Y, for example (Fig. 14) was consistently lower than the others for the lateral task, and pilot $\mathrm{U}$ was consistently lower for the vertical task. To form a single score for pilot performance it was noted that for all pilots the overall RMS lateral error was roughly 12 times the overall RMS vertical error. A resultant vector score was then found for each pilot as $\sqrt{(\text { Lateral score })^{2+}}$ (12 Vertical score $)^{2}$. The results of these calculations are shown in Fig. 15. It can be seen that pilot $Y$ had the lowest overall score with the smallest amount of difference between the wind and no-wind conditions. Pilot $U$ had the second to the lowest overall mean score but the difference between his wind and no-wind scores was the largest of the group. This comparison points out the difference in technique between these two pilots. Pilot $\mathrm{Y}$ approached the problem as one task, while pilot U gave primary attention to altitude. An analysis of variance of these scores showed the same results as summarized in Tables III and IV and 1 is not included.

The differences in performance among the pilots as they fell into the preference groups were quite small and were not statistically significant. These performance data are not shown.

No particular significance can be attached to the map orientation pilot interaction shown in Tables III and IV. Fig. 16 shows that although the largest block of learning for this task was made during the practice day, there was still a steady indication of learning through- 
out the experiment. So with the balanced experimental sequence used (Table I) it would be expected that how well a pllot performed with a given orientation relative to the other two orientations would be related to where that orientation appeared in the sequence.

The presence of the significant wind-pilot interaction can be seen in Figs. 14 and 15. It is clear that there was a wide range in the ability to cope with the presence of wind in the task.

An expected interaction between orientation and wind was not shown by the data. The pilot comments did not indicate any particular advantage with any display orlentation in correcting for wind. One pilot did indicate that it was slightly easier to keep track of the wind direction on $\mathrm{O}_{1}$ and $\mathrm{O}_{3}$, and two pilots indicated a wind vector on all maps would be helpful.

The significant differences in performance between the pilots and their differences in ability to handle the wind conditions is not surprising. Differences in ability are accepted as a fact in any population. What was slightly surprising was the small value of some of the errors which indicates the potential accuracy of such displays. (Of course this does not include potential operational errors due to ground and airborne equipment errors.) For example, Pilot $\mathrm{Y}$ had an overall average lateral RMS score for all conditions without wind of 39 meters (128 ft.). This is even more impressive when this is translated to the actual error distance on the face of the display. With the $1.6 \mathrm{n} . \mathrm{mi} / \mathrm{in}$. scale that was used, this was a calculated $.033 \mathrm{~cm} .(.013 \mathrm{in.})$ error on the display. 
This is close to the width of the display line elements themselves. This points out that very small differences between the required ground track and the parallel element of the aircraft symbol can be detected. (Pilot Y made two runs where RMS errors were only about half his average value.)

Fascination: One of the pilots (Y) demonstrated atypical behavior on two different runs with the fixed, north-up map. Such events could not be planned in an experiment, but having occurred they provide valuable insight into this pilot's approach to his task and also 1llustrate the potential for blunder with a north-up map display. Fig. 10 is a drawing showing the ground track for the two runs relative to the reference track. Track A was the fifth run of the day (not counting practice) and was flown with the over-under display location. Track B was the elghth run of the day and used a side-by-side location. Both tracks were flown with the "no-wind" condition. Track B was the next "no-wind" run after track A. This pilot normally flew ground tracks with a sma11 error under the "no-wind" conditions. He was, in fact, the most proficient tracker of the six pilots. (The data from these two runs were not included in the overall performance data analysis.)

On track A the turn to go from the $135^{\circ}$ leg to the $180^{\circ}$ leg was initiated at the proper time -- in the wrong direction. Then there was a pause in action for a short time while the aircraft maintained a heading of about $100^{\circ}$. About 8 seconds after the initiation of the turn in the wrong direction he called on the intercom and asked if the run could be aborted. He was reminded of the instructions to complete all flights except in the case of equipment malfunction. Following the run he had 
two comments. First, the task was getting too easy and he was "fine controlling" at the expense of "thinking." Secondly, it was easy to "recover" with this presentation, 1.e., easy to see where he had to go to get back on the track, once off the track. After completing track B there was no further comment other than a disgusted acknowledgement that he had "done it again." Though $1 \mathrm{t}$ is seldom as clear cut as in these examples this behavior is not unique and seems to be aptly described by the term "fascination" as defined by Clark and Graybiel (4). "In these situations (involving fascination) the pilot had his attention so intently on one item that he did not attend to other items of importance during the flight." Pllot $\mathrm{Y}$ was, in fact, always intent on "bettering his scores."

\section{Post Experiment Questionnaire}

At the end of their last day each pilot was asked a set of questions concerning the experiment. The procedure took the form of a structured interview.

They were first asked to rank order the six conditions in order of preference. There was some protest to this with comments that there "really wasn't that much difference" between some of the conditions. Table II is a tabulation of the rankings. The number one indicates a first choice, two a second choice, etc. As a coarse means of comparing subgroups these numbers were treated as being "equal interval" and simply added together. A higher total indicates a lower average preference. 
The first thing to note in Table II is the wide varlety of opinion. No column shows more than two selections of the same ranking. In fact, within the first, fourth and fifth columns there are an equal number of first and last place rankings. It can be seen by looking at the pilot preference group subtotals for the over-under and side-by-side placement that there is essentially no difference for elther preference group. Looking at the map orientation results, the heading up orientation $\left(0_{2}\right)$ seems to hold a very slight overall edge in preference.

There were specific reasons behind these differences of opinion as can be seen by their responses when asked to list a major pro and con for each display. Appendix B summarizes these responses from all pilots concerning the three different map orientations. It can be seen that there are valid strangths and weaknesses to be considered for each one. The comments of one of the pilots who had experienced mild vertigo with the heading up orientation $\left(\mathrm{O}_{2}\right)$ are especially interesting. He normally preferred the side-by-side placement because the scan "was more relaxed," but preferred the over-under placement with $\mathrm{O}_{2}$ because there was "Iess distraction" from the motion. The effect was strong enough that this pilot ranked $\mathrm{O}_{2}$ with over-under placement as his first choice, and $\mathrm{O}_{2}$ with side-by-side placement as his last cholce.

The over-under/side-by-side preference can be most easily summarized as a difference of opinion regarding whether it is easier to scan sideways or vertically. Four of the six pilots, two in each preference group, answered that it was easier to scan "sideways" and expressed a slight preference for the side-by-side position. The other two pilots maintained that vertical scan was easier. One of the pilots that 
preferred the side-by-side position and was in the original over-under preference group, expressed mild surprise in finding he actually preferred the side-by-side condition for flying.

Five questions were intended to elicit comments about the display content and method of its presentation. The most general comment was that they liked both displays (VSD and map) better after using them for awhile than they thought they would at the beginning of the experiment. The display element most commented upon was the altitude error bar. Three pilots said to delete 1 t and another said to change it some way or delete it. Two commented that it simply was not needed (i.e., sufficient information was available from the altimeter and vertical speed Indicator (VSI) and added clutter, while two commented that they wanted the information but this presentation was "somehow confusing." The following is a listing of the other more pertinent comments.

"A wind vector arrow on map would help." (2)

"On map show heading for lext leg."

"VSI should be other than digital." (2)

"For over-under displays put digital readouts at the bottom of the VSD."

"Would prefer an analog heading."

"Make (+) and (-) signs larger in front of VSI."

"The less cluttered you keep the map display, the quicker you will be able to pick up the aircraft."

They generally agreed to the "realism" of the display and were of , the opinion that their preferences and comments would be the same in a 
flight situation. They all felt that they were doing a "reasonably good job" by the second day but were still improving some at the end of the experiment.

Five of them answered that they would find a CRT map display to be useful in their present aircraft. The "no" answer was for current ATC procedures, but changed to "yes" for more crowded airspace. They would find it most useful for terminal area use such as fixed transitions, holding patterns, etc. They felt it would cut down on cockpit workload by releiving the "mental" load of planning ahead.

\section{CONCLUDING REMARKS}

The results of a study designed to investigate the effects of two HSD/map panel locations, relative to the VSD, and of three map orientations have been presented. Both pilot performance results and Post Experimental Questionnaire results have been discussed. Based on these results the following conclusions and recommendations are indicated.

Considering both the performance data and the results of a Post Experimental Questionnaire it is concluded that either of the VSD-map display locations used in this experiment would be satisfactory as an instrument panel location. Either choice might meet some resistance at first but the adaptation time to either would be short.

The general performance data indicate that there is nothing to choose from among the three map display orientations. There were no significant differences in performance among the orientations and there was no indication that any one of the three gave either an advantage or disadvantage in keeping track of the wind directions. The pilot comments throughout the experiment and the answers to the Post 
Experiment Questionnaire indicate, however, that there are further considerations to be made in the choice of a map orientation. Each orientation has at least one definite advantage and disadvantage. The emphasis on each varied widely among the pilots (Table II). Further research is needed to determine the relative importance of these advantages and disadvantages. Specifically, the use of these map display orfentations needs to be evaluated in other phases of flight, such as enroute and transition from enroute to terminal areas. This evaluation should be done in the workload context of a more complete mission simulation than was used for this experiment. The following comments and recommendations concerning map orientation are based strictly on the results of this experiment.

The flxed north-up orientation with a moving afrcraft $\left(0_{1}\right)$ provided the pilots with a stable map which they generally liked. However, there seemed to be more of a need to plan ahead. Also, there was less feeling of direct identification with the aircraft symbol than was the case with $\mathrm{O}_{2}$. The data show that good performance on this type of task is possible, but the possible outcome of a lapse of attention has been shown by the performance previously described in Fig. 10. This orientation is probably best suited for use where the map display is primarily used for planning purposes, 1.e., outer loop as opposed to inner loop control.

The rotating map with fixed center aircraft $\left(\mathrm{O}_{2}\right)$ would at first appear to have the best combination of advantages. There is always leftright control compatibility, the aircraft is readily located at the center of the display and there is always an equal amount of terrain shown 
around the aircraft. These features are balanced against an unexpected objection to the motion of the display background. Three pilots mentioned a tendency to vertigo; one adapted fairly quickly to where it did not bother him, while the other two continued to be disturbed by it. The conflict seems to stem from the presentation in the single frontal plane of two moving fields representing two different planes. Rotation of large areas in the frontal plane is usually associated with aircraft roll and part of the conflict may be due to a lack of adaptation to this new mode of presentation. This orientation may be the one best suited to be used as an instrument for direct quidance of the aircraft. More study and experience is needed to determine the importance of the potential vertigo problem. The third orientation, north-up with moving map and rotating aircraft $\left(0_{3}\right)$, was originally included in the experiment as sort of a "worst case", with a combination of "inside-out" and "outside-in" elements as already explained. In actual use, however, with the map scaling of $1.6 \mathrm{n}$. mi./in., the background moved so slowly that it was very little different than the $0_{1}$ orientation with basically the same pros and cons. The ratings for this orientation (Table II) generally fell between those for $0_{1}$ and $0_{2}$ and seemed, therefore, to be a compromise choice. This orientation is recommended primarily for planning purposes, the same use as $0_{1}$. In an operational environment it would have the added advantage that the aircraft would never fly off the edge of the display, i.e., there would be no map frame changes with the air- 
craft jumping to a new spot on the screen. The aircraft is always at the center of the display.

Generally, the pilots were quite receptive to the idea of using such displays. Those with some prior reservation seemed to have changed their opinion by the end of the practice day. The consensus was that any one of these map displays would be of help for planing purposes, particularly in terminal areas.

These conclusions and recommendations are for the display elements as they were used in this experiment. Addition of other information elements such as flight directors, predictors, etc., could significnatly alter these conclusions. 
APPENDIX A

\section{Display Location Preference Questionnaire}

While planning this experiment it was recognized that pilot attitudes regarding relative display placement, i.e., over-under vs. sideby-side, could conceivably be a factor in their performance with the two display placements. It was decided to control for this difference, if it did exist, by selecting two groups of pilots on the basis of their responses to a questionnaire mailed to their home. It was anticipated that the larger percentage of the pilots would prefer the over-under arrangement, so in order to increase the chances of filling the sideby-side preference group the questionnaire was sent to three times as many pilots as were needed, nineteen of the pilots contacted by phone. Al1 pilots responded, sixteen of them with complete questionnaires. Preference ranking was possible for 18 pilots. Based on the identifying letter labels shown in Fig. 8, the following preference orders were obtained. Ten pilots ordered the choices by CBA; five pilots by BCA; two pilots by $\mathrm{ACB}$; and one pilot by $\mathrm{BAC}$. Two pilots from $\mathrm{BCA}$ and one from ACB were chosen for Preference Group A, 1.e., the side-by-side preference group, and three pilots from CBA were chosen for Preference Group B, the over-under preference group. Strength of preference and availability both entered into the final choice of pilots. 


\section{APPENDIX B}

\section{PILOT COMMENTS ABOUT MAP ORIENTATIONS - SUMMARY}

North up with moving aircraft symbol $\left(\mathrm{O}_{1}\right)$

Pro: Stable map - (3)*

Easier to figure wind corrections (1)

No response (2)

Con: Had to think some about left-right turns (4)

Left him detached from aircraft (1)

Hard to locate aircraft quickly on scan (1)

Aircraft heading up $\left(\mathrm{O}_{2}\right)$

Pro: Instant orientation regarding direction to turn (3)

Easier to identify with aircraft position (2)

Always know where aircraft located, i.e., at center (1)

Better turn rate information (1)

Con: Didn't like the motion and rotation - tendency to vertigo (3)

Aircraft heading not obvious (1)

No response (2)

North up with moving map $\left(\mathrm{O}_{3}\right)$

Pro: Easy to locate aircraft, i.e., always at center (2)

Stable picture (2)

Liked to see ground move (1)

Easier to figure out wind corrections (1)

Con: Did not like map to move - lose parts (3)

Had to think some about left-right turns (2)

Neutra1 (1)

* = Number of Responses 
1. Norman S. Selsby and Michael C. Fischer, "A simulator study of a pictorial navigation display in instrument departures of the supersonic transport." NASA TN D-4029, July 1967.

2. S. N. Roscoe, "The navigation director: an area navigation system." Hughes Aircraft Company TM-898, June 1968.

3. James R. Gannett, "Flight management concept II." 1970 Human Factors Society Annual Meeting, San Francisco, California, October 13-16, 1970.

4. Brant Clark and Ashton Graybiel, "Vertigo as a cause of pilot error in jet aircraft." The Journal of Aviation Medicine, Volume 28, pp. 469-478, October 1957. 
TABLE I - EXPERIMENTAL SEQUENCE SUMMARY

\begin{tabular}{cccccc}
$\begin{array}{l}\text { Preference } \\
\text { Group }\end{array}$ & Pilot & Training & \multicolumn{3}{c}{ Experiment } \\
\hline A & $\mathrm{S}$ & Day & Day & Day 2 & Day 3 \\
(Side-by-side) & $\mathrm{T}$ & $0_{1}$ & $0_{2}$ & $0_{3}$ & $0_{1}$ \\
& $\mathrm{U}$ & $0_{2}$ & $0_{3}$ & $0_{1}$ & $0_{2}$ \\
& $\mathrm{U}$ & $0_{3}$ & $0_{1}$ & $0_{2}$ & $0_{3}$ \\
\hline \multirow{2}{*}{$\mathrm{B}$} & $\mathrm{X}$ & $0_{1}$ & $0_{3}$ & $0_{2}$ & $0_{1}$ \\
(Over-under) & $\mathrm{Y}$ & $0_{2}$ & $0_{1}$ & $0_{3}$ & $0_{2}$ \\
& $\mathrm{Z}$ & $0_{3}$ & $0_{2}$ & $0_{1}$ & $0_{3}$ \\
\hline
\end{tabular}


TABLE II - POST EXPERIMENT PILOTS RATINGS ${ }^{*}$ FOR DISPLAY COMBINATIONS

\begin{tabular}{|c|c|c|c|c|c|c|c|}
\hline \multirow{2}{*}{$\begin{array}{l}\text { Pref erence } \\
\text { Group }\end{array}$} & \multirow[b]{2}{*}{ Pilot } & \multicolumn{3}{|c|}{$\begin{array}{l}\text { Over-Under } \\
\text { P1acement }\end{array}$} & \multicolumn{3}{|c|}{$\begin{array}{l}\text { Side-by-Side } \\
\text { Placement }\end{array}$} \\
\hline & & $\overline{0_{1}}$ & $0_{2}^{* *}$ & $0_{3}$ & $0_{1}$ & $0_{2}$ & $0_{3}$ \\
\hline \multirow{5}{*}{$\begin{array}{l}\text { A } \\
\text { Side-by-side }\end{array}$} & S & 4 & 2 & 6 & 3 & 1 & 5 \\
\hline & le & 1 & 5 & 3 & 2 & 6 & 4 \\
\hline & $\mathrm{U}$ & 6 & 2 & 4 & 5 & 1 & 3 \\
\hline & $\begin{array}{l}\text { Sub } \\
\text { Total }\end{array}$ & 11 & 9 & 13 & 10 & 8 & 12 \\
\hline & $\begin{array}{l}\text { Group } \\
\text { Tota1 }\end{array}$ & \multicolumn{3}{|c|}{33} & \multicolumn{3}{|c|}{30} \\
\hline \multirow{5}{*}{$\begin{array}{l}\text { B } \\
\text { Over-under }\end{array}$} & $\mathrm{x}$ & 5 & 1 & 2 & 4 & 6 & 3 \\
\hline & $\mathrm{Y}$ & 5 & 1 & 3 & 6 & 2 & 4 \\
\hline & $\mathrm{z}$ & 4 & 6 & 5 & 1 & 3 & 2 \\
\hline & $\begin{array}{l}\text { Sub } \\
\text { Total }\end{array}$ & 14 & 8 & 10 & 11 & 11 & 9 \\
\hline & $\begin{array}{l}\text { Group } \\
\text { Total }\end{array}$ & \multicolumn{3}{|c|}{32} & \multicolumn{3}{|c|}{31} \\
\hline Conditions & Total & 25 & 17 & 23 & 21 & 19 & 21 \\
\hline
\end{tabular}

*Most preferred was 1 and least preferred was 6 .

$* *$ Map orientations

$0_{1}=$ North-up with moving aircraft symbol

$0_{2}=$ Aircraft heading up

$0_{3}=$ North-up with moving map 
TABLE III - ANALYSIS OF VARIANCE - LATERAL SCORES

\begin{tabular}{|c|c|c|c|c|}
\hline & $\underline{\mathrm{ss}^{1}}$ & $\underline{\mathrm{dF}^{2}}$ & $\underline{\mathrm{MS}^{3}}$ & $\mathrm{~F}$ \\
\hline Map Orientation (0) & 4,610 & 2 & 2305 & $<1$ \\
\hline Display Location (D) & 37 & 1 & 37 & $<1$ \\
\hline Wind (W) & 270,512 & 1 & 270,512 & $47.72 * *$ \\
\hline Pilots (P) & 64,687 & 5 & 12,937 & $14.39 * *$ \\
\hline Groups ${ }^{t}$ & 54 & 1 & 54 & $<1$ \\
\hline $0 \times D$ & 214 & 2 & 107 & $<1$ \\
\hline $0 \times \mathrm{W}$ & 2392 & 2 & 1196 & 1.60 \\
\hline$D \times W$ & 33 & 1 & 33 & $<1$ \\
\hline $0 \times P$ & 23,523 & 10 & 2352 & $2.62 * *$ \\
\hline$D \times P$ & 2,838 & 5 & 568 & $<1$ \\
\hline$W \times P$ & 28,341 & 5 & 5668 & $6.30 * *$ \\
\hline$O \times D \times W$ & 599 & 2 & 299 & $<1$ \\
\hline$O \times D \times P$ & 7788 & 10 & 779 & $<1$ \\
\hline $0 \times W \times P$ & 7475 & 10 & 747 & $<1$ \\
\hline$D \times W \times P$ & 4573 & 5 & 914 & 1.02 \\
\hline$O \times D \times W \times P$ & 9370 & 10 & 937 & 1.04 \\
\hline $\begin{array}{l}t=\text { Separate test } \\
1=\text { Sum of squares } \\
2=\text { Degrees of Freedom } \\
3=\text { Mean square } \\
\star *=\text { Significant at } .01 \text { level }\end{array}$ & & & & \\
\hline
\end{tabular}


TABLE IV - ANALYSIS OF VARIANCE - VERTICAL SCORES

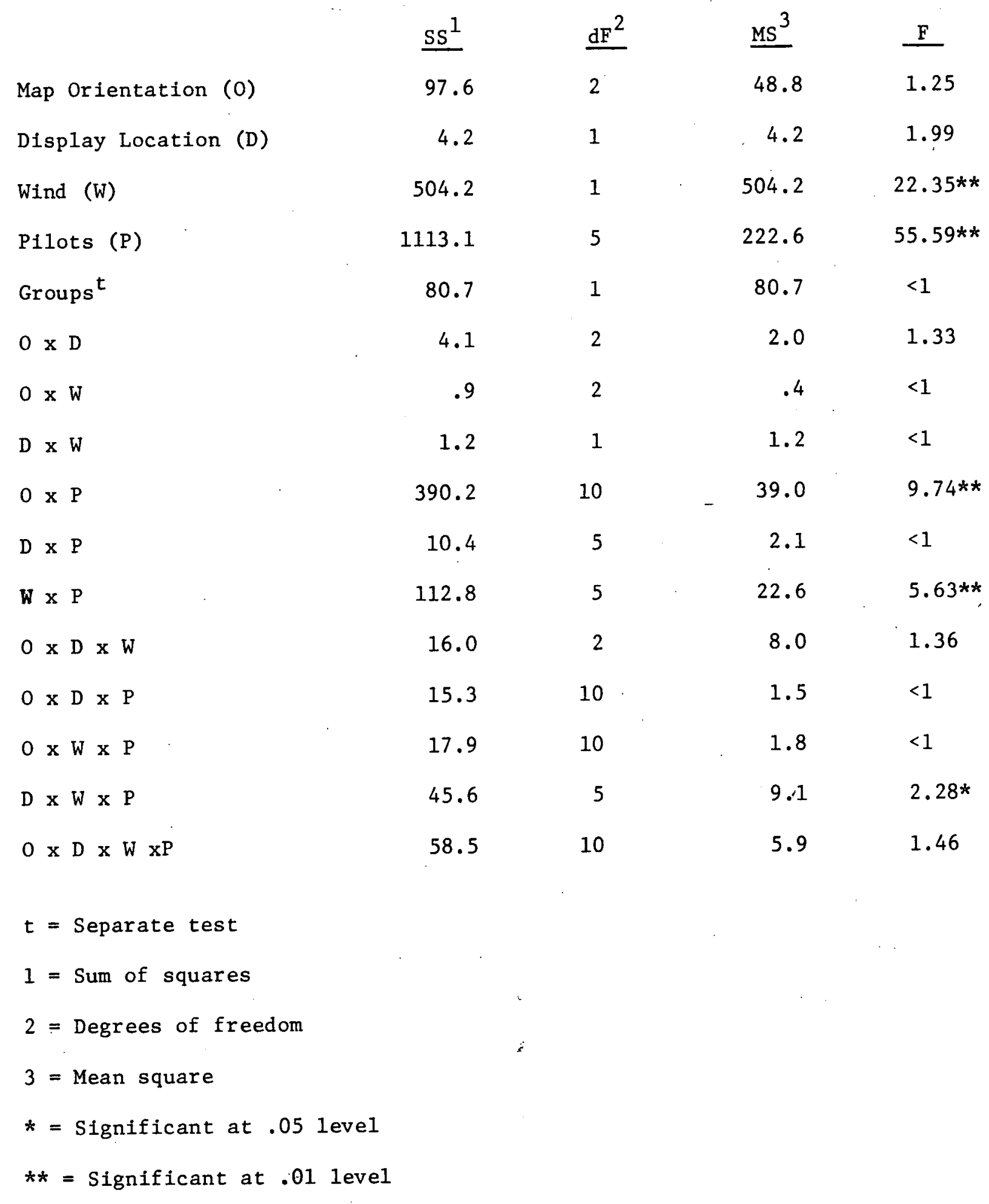




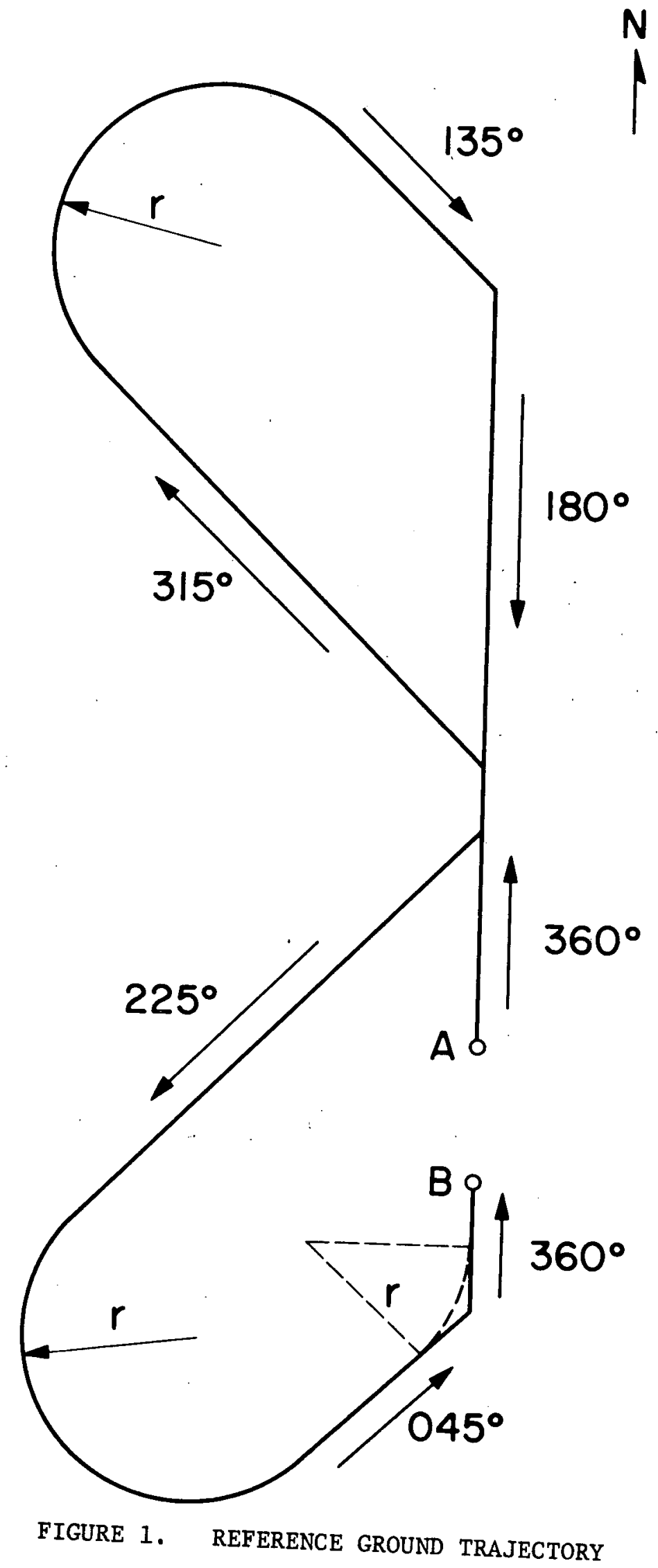




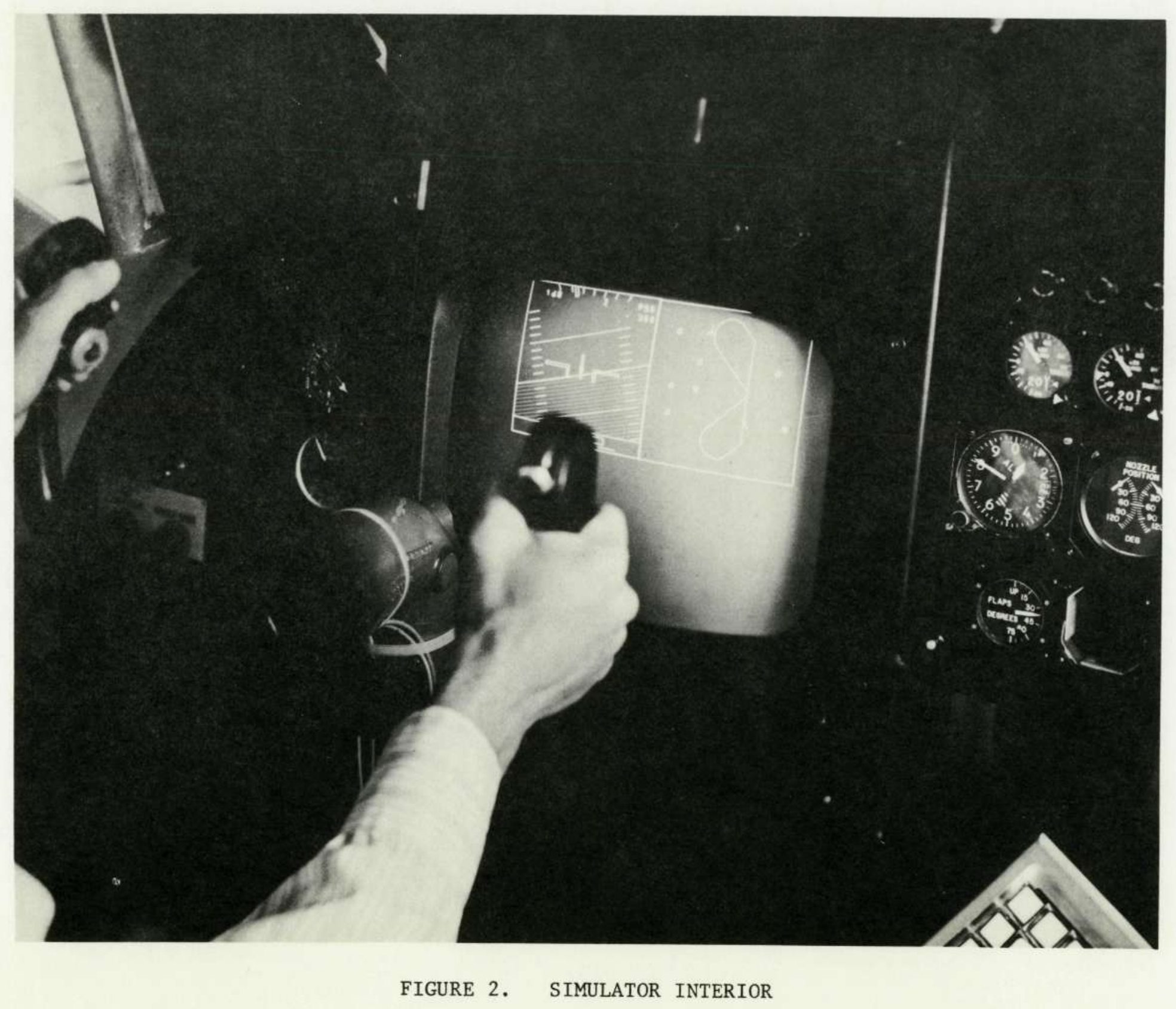

$n$ 


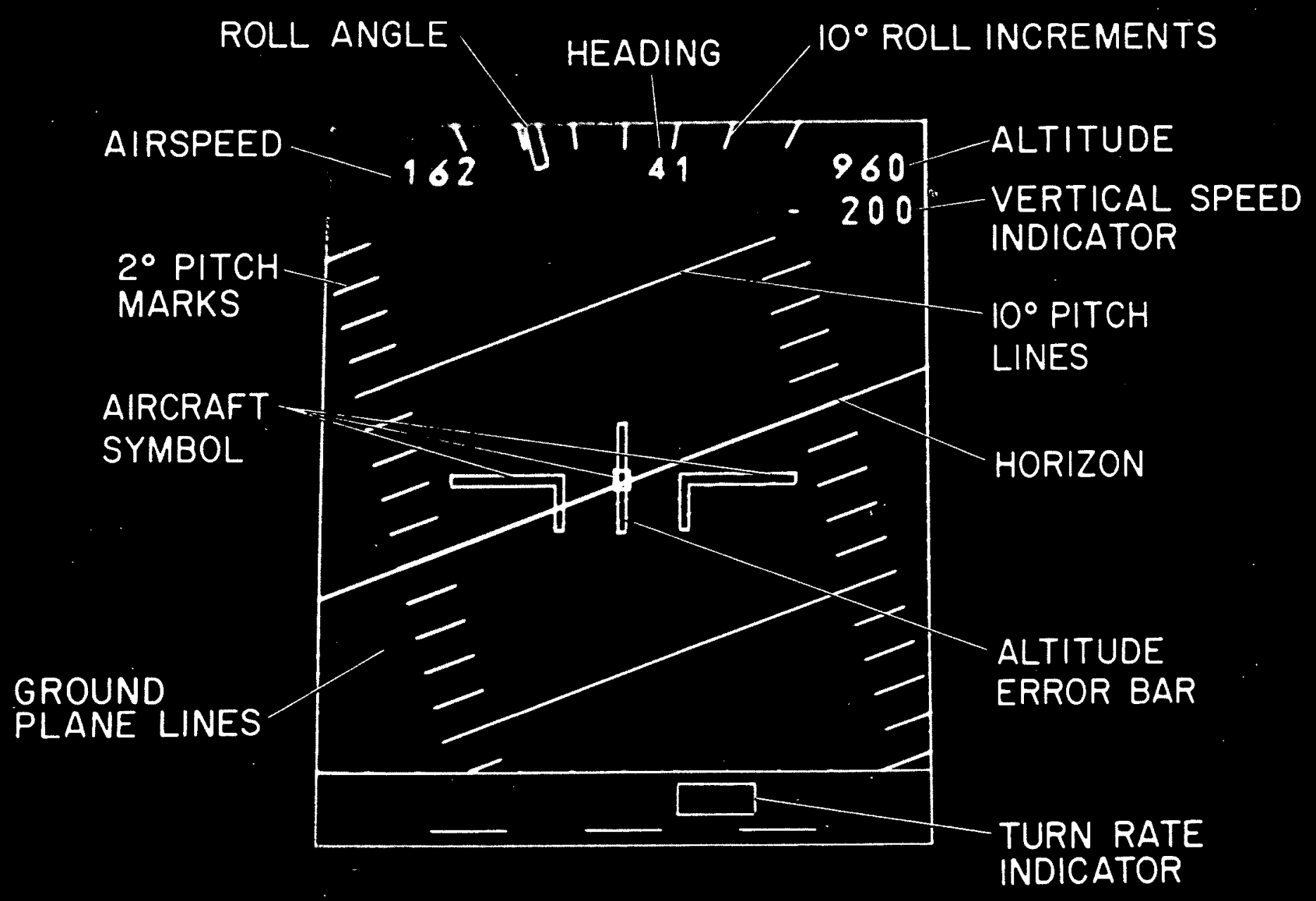

FIGURE 3. ELEMENTS OF THE VERTICAL SITUATION DISPLAY 


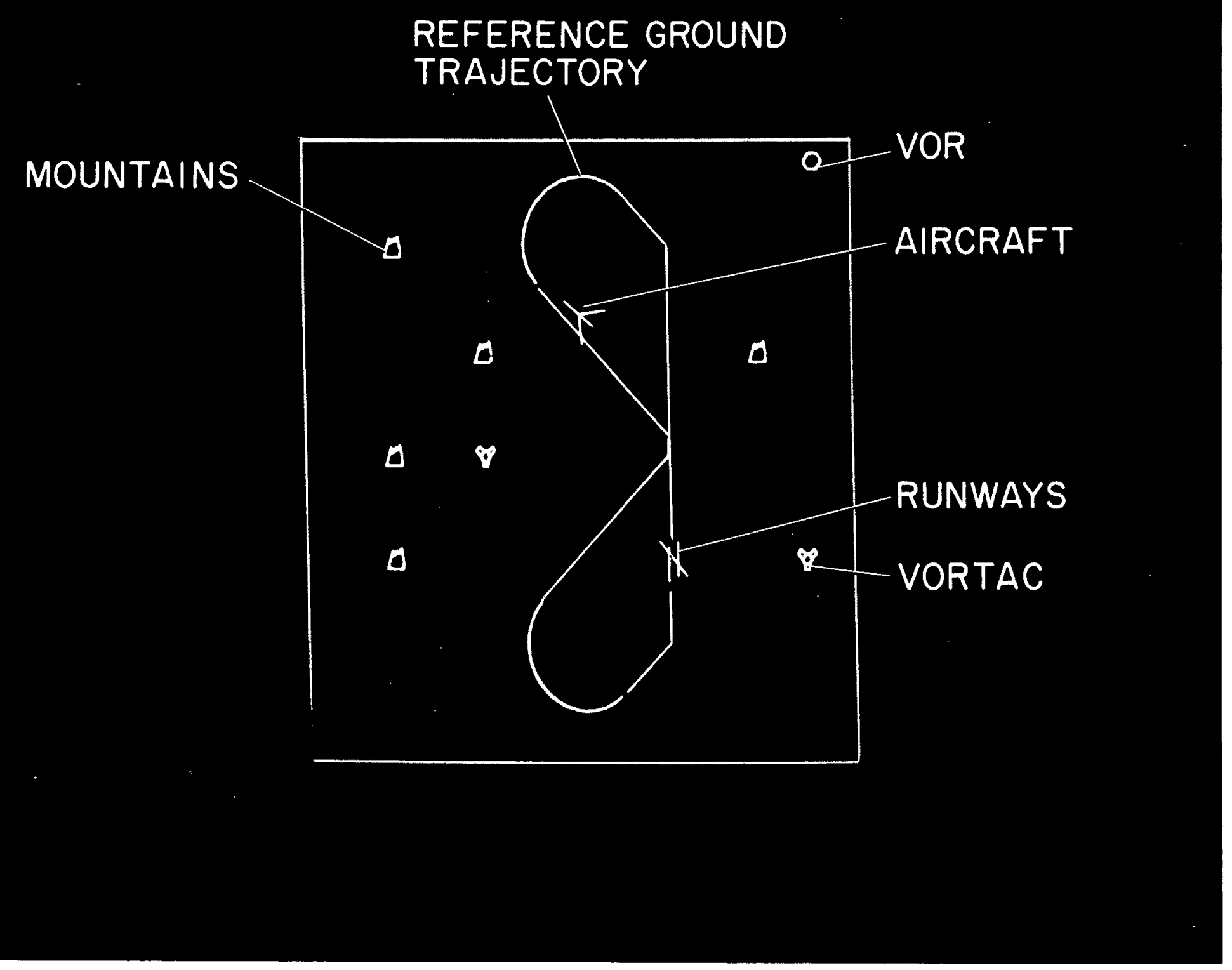

FIGURE 4. ELEMENTS OF THE HORIZONTAL SITUATION DISPLAY 


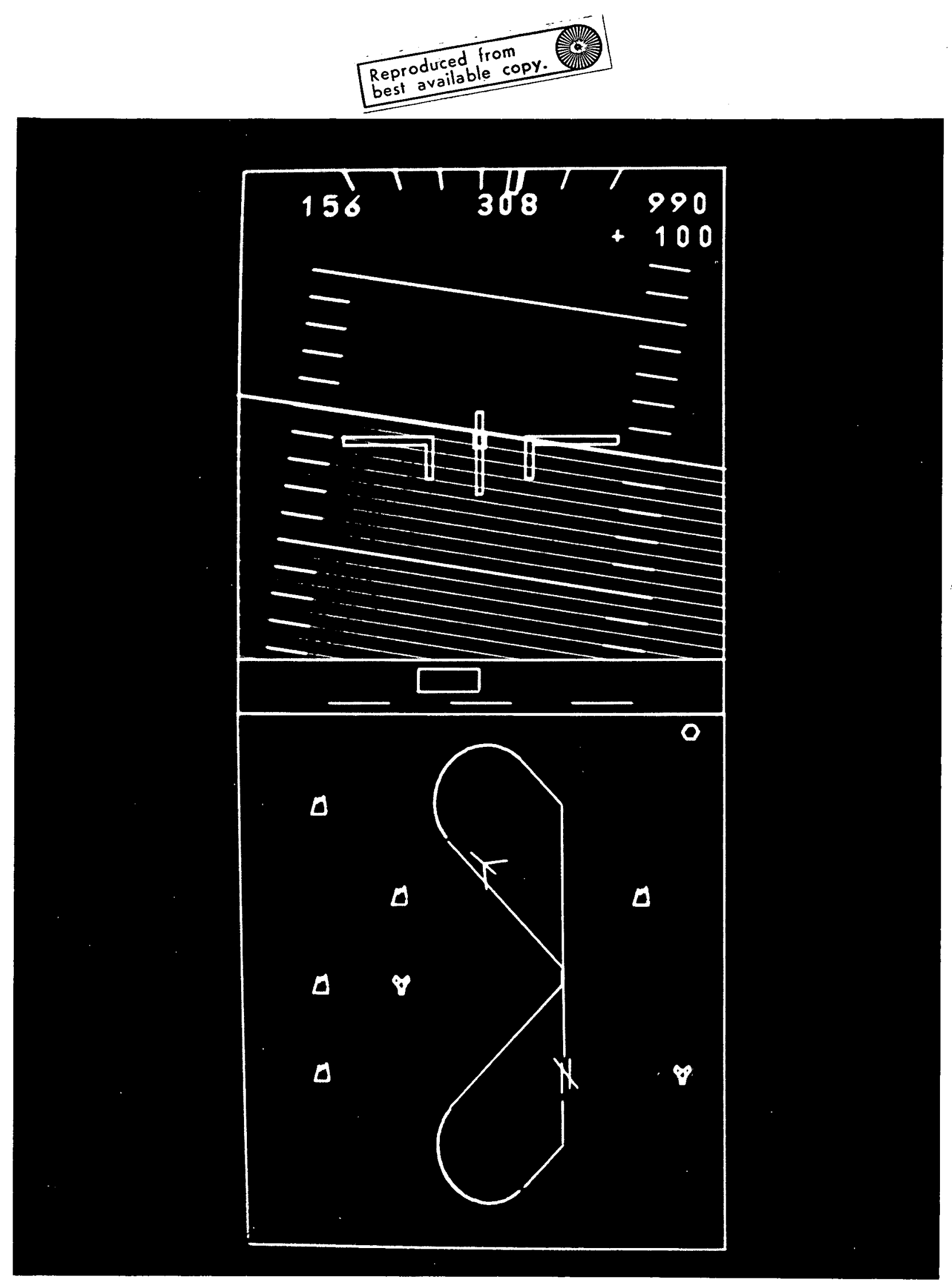

FIGURE 5. OVER-UNDER DISPLAYS; NORTH-UP FIXED-MAP 


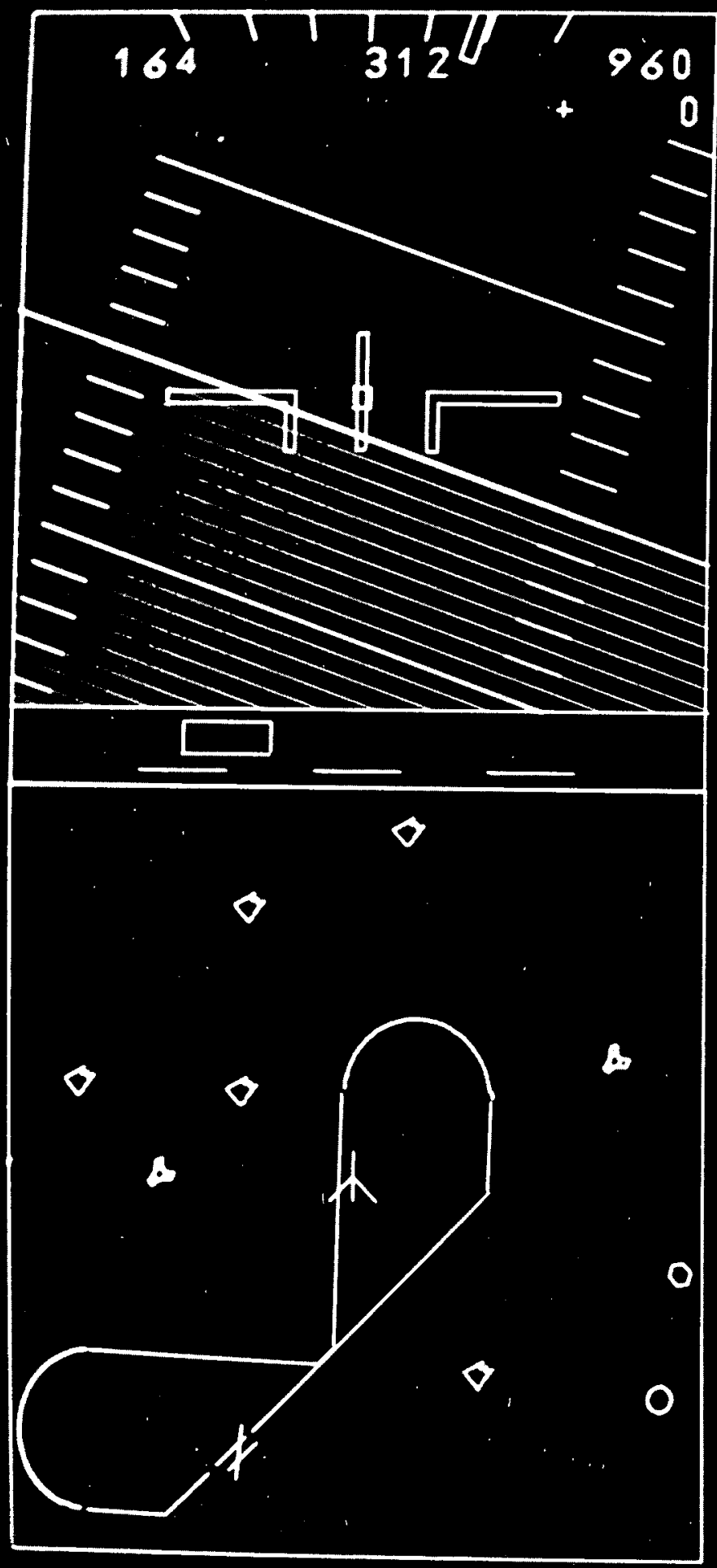

FIGURE 6. OVER-UNDER DISPLAYS; AIRCRAFT HEADING UP TRANSLATING AND ROTATING MAP 


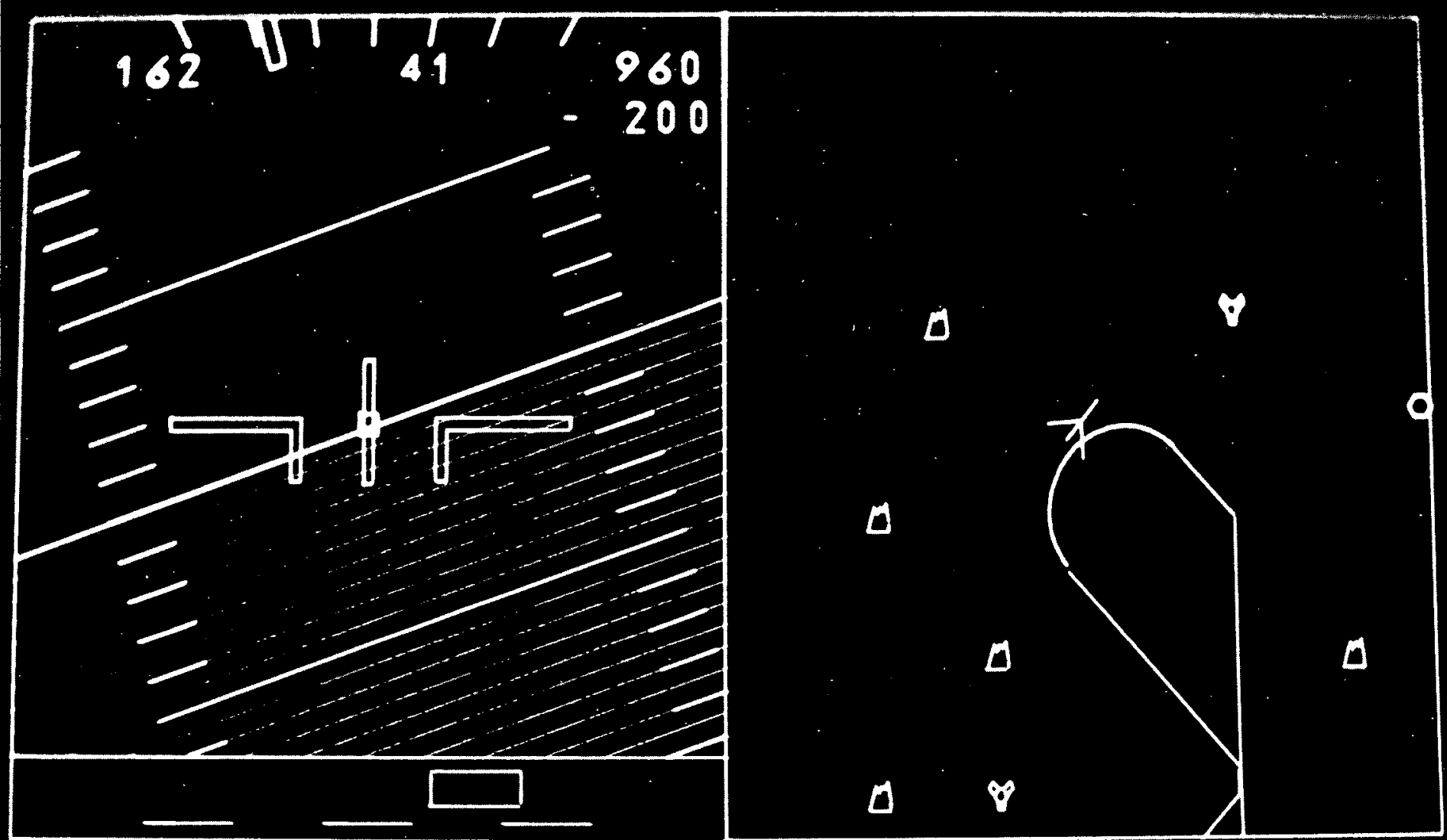

FIGURE 7. SIDE-BY-SIDE DISPLAYS; NORTH-UP TRANSLATING MAP 
NAME

DATE

DISPLAY LOCATION PREFERENCE

Below are three pairs of relative display locations or orientations. For each pair choose the display orientation you prefer. If you have no reason for choosing either one, then mark "No Preference." ( $\mathcal{E}$ refers to the location of the pilot's center line-of-sight.)

1.

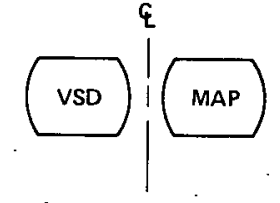

A

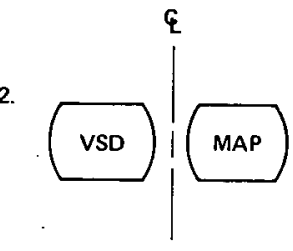

A<smiles>[Y5]C1(C2([Y16])CCCC(C)([As])CC2)CCCC(C)(C)CC1</smiles>
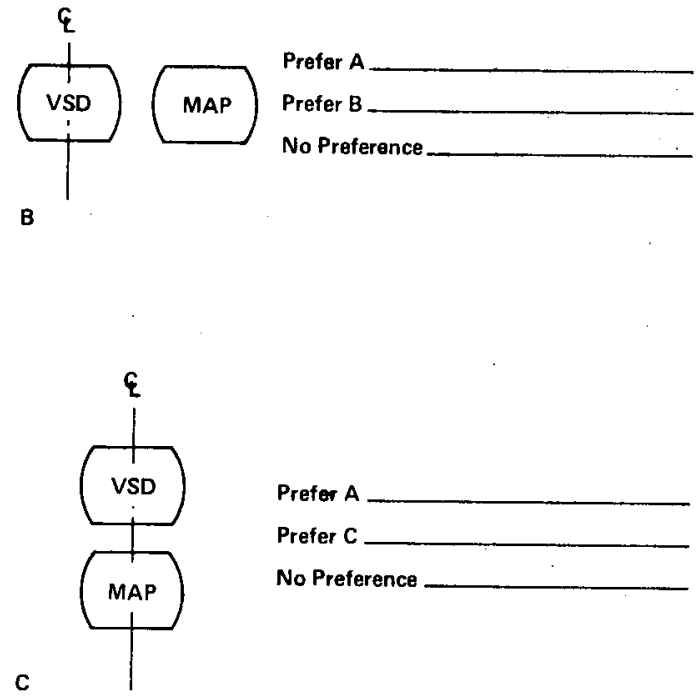

FIGURE 8. PAIRED COMPARISON SECTION OF PRE-EXPERIMENT QUESTIONNAIRE 


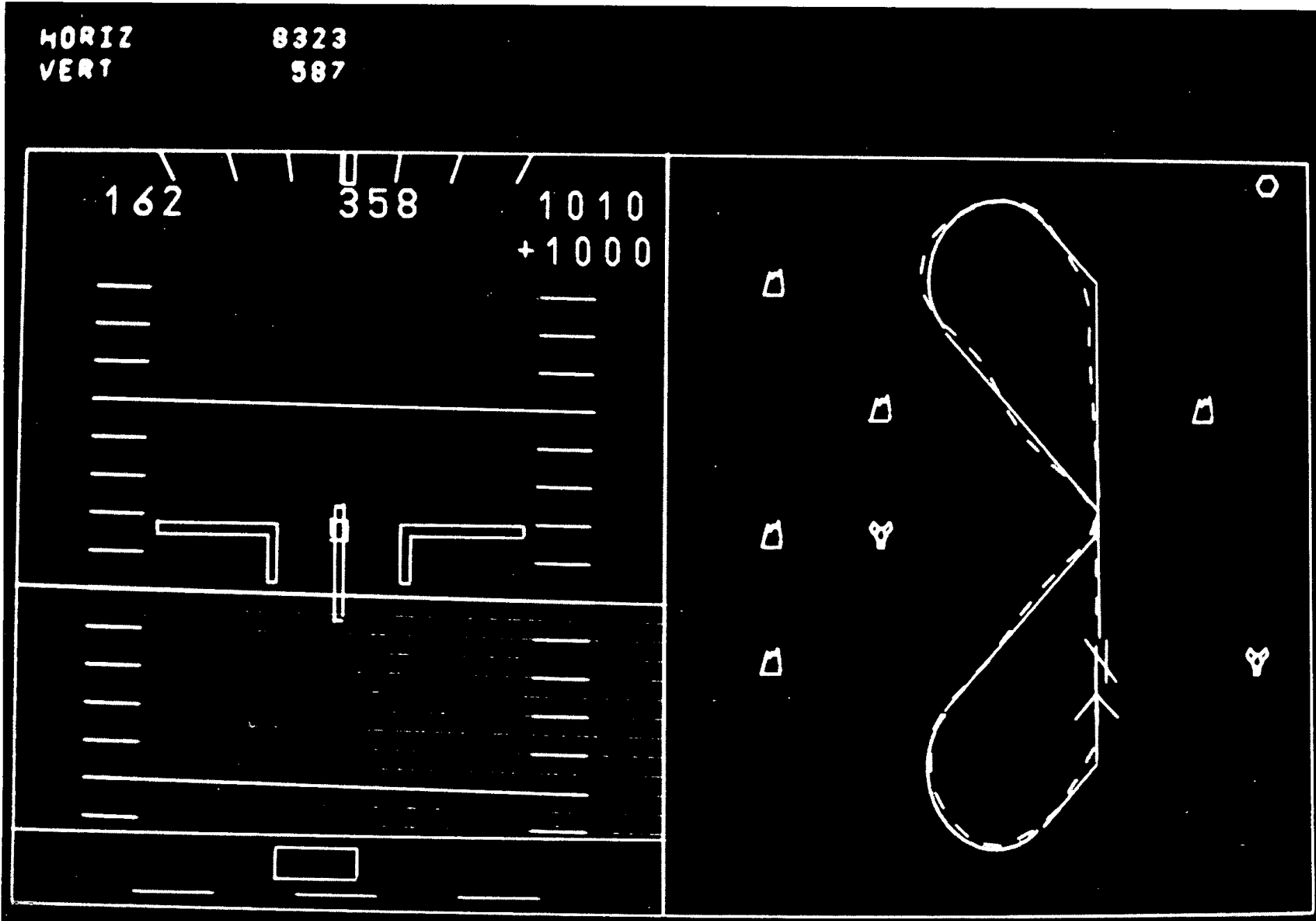

FIGURE 9. END-OF-FLIGHT RESULTS 


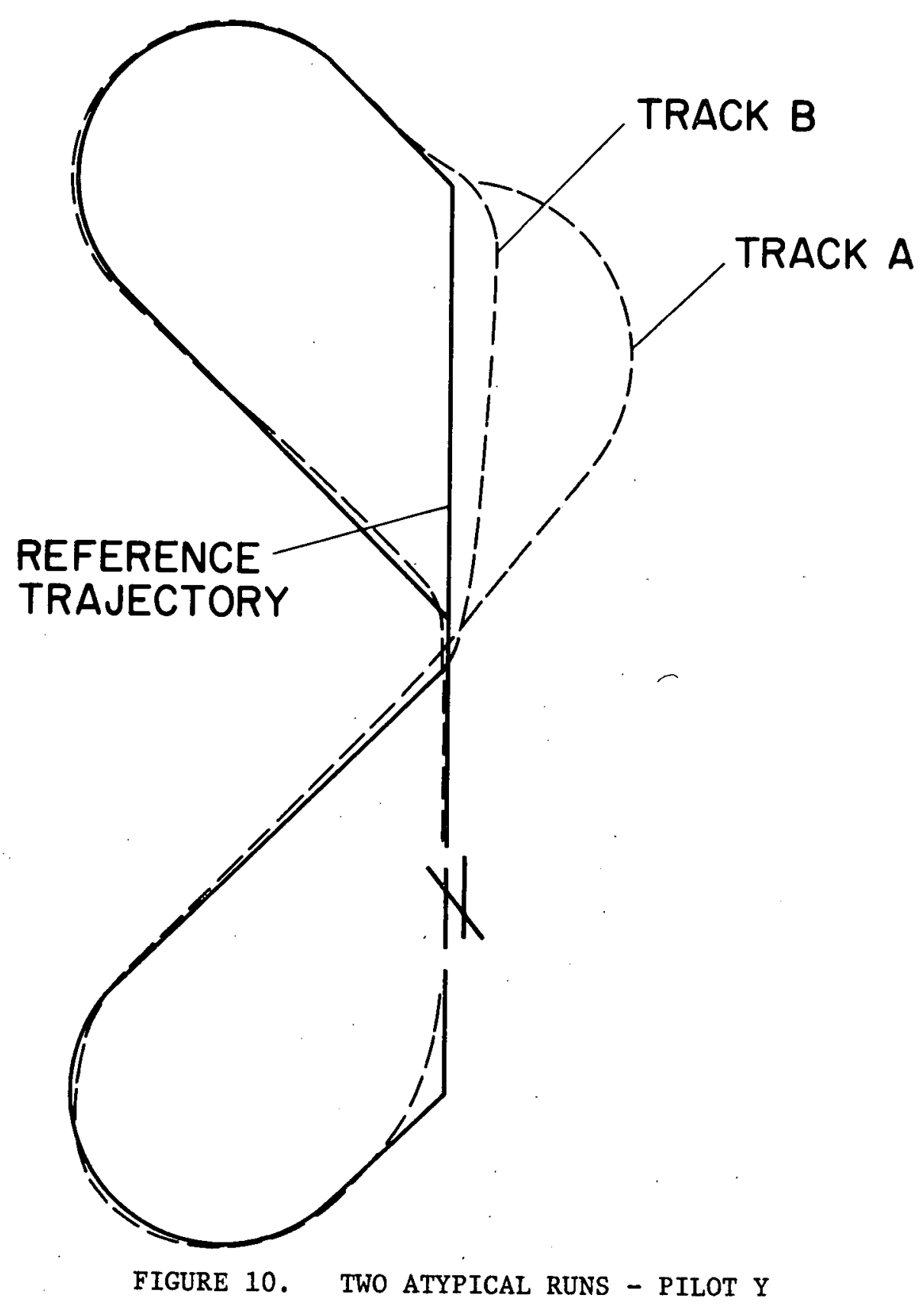




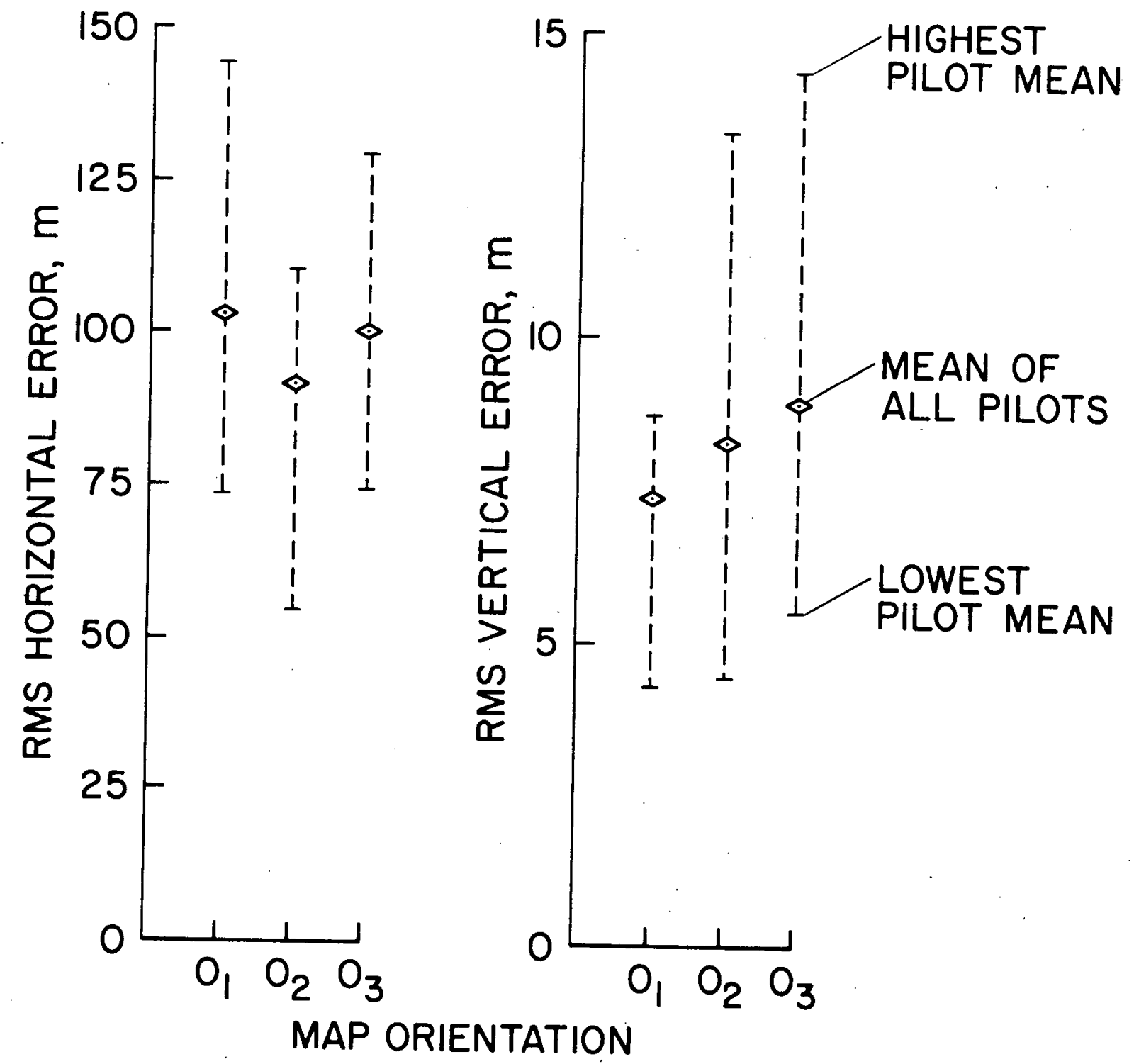

FIGURE 11. PILOT PERFORMANCE - THREE MAP ORIENTATIONS - SIX PILOTS 


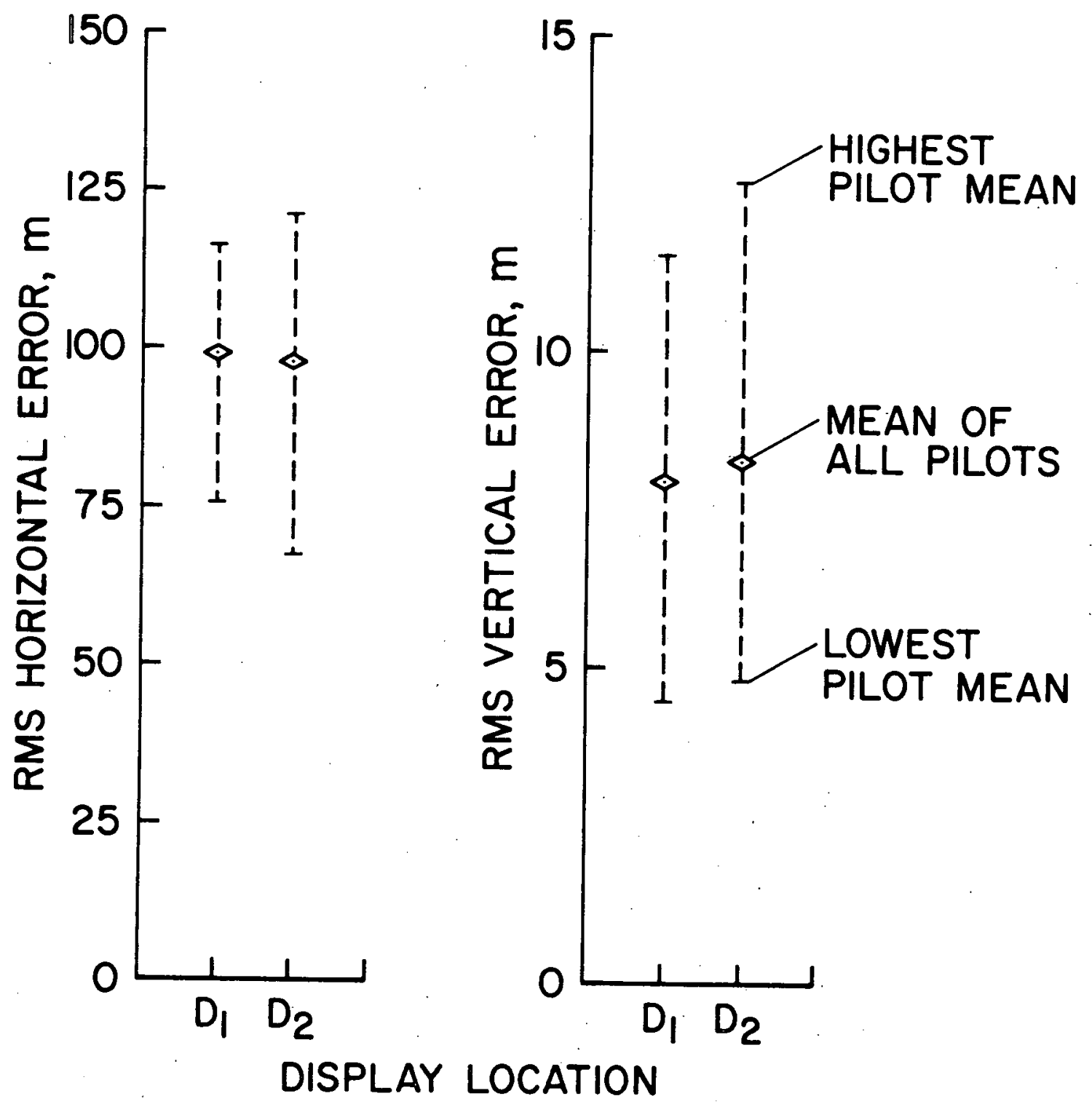

FIGURE 12. PILOT PERFORMANCE - TWO DISPLAY LOCATIONS - SIX PILOTS 


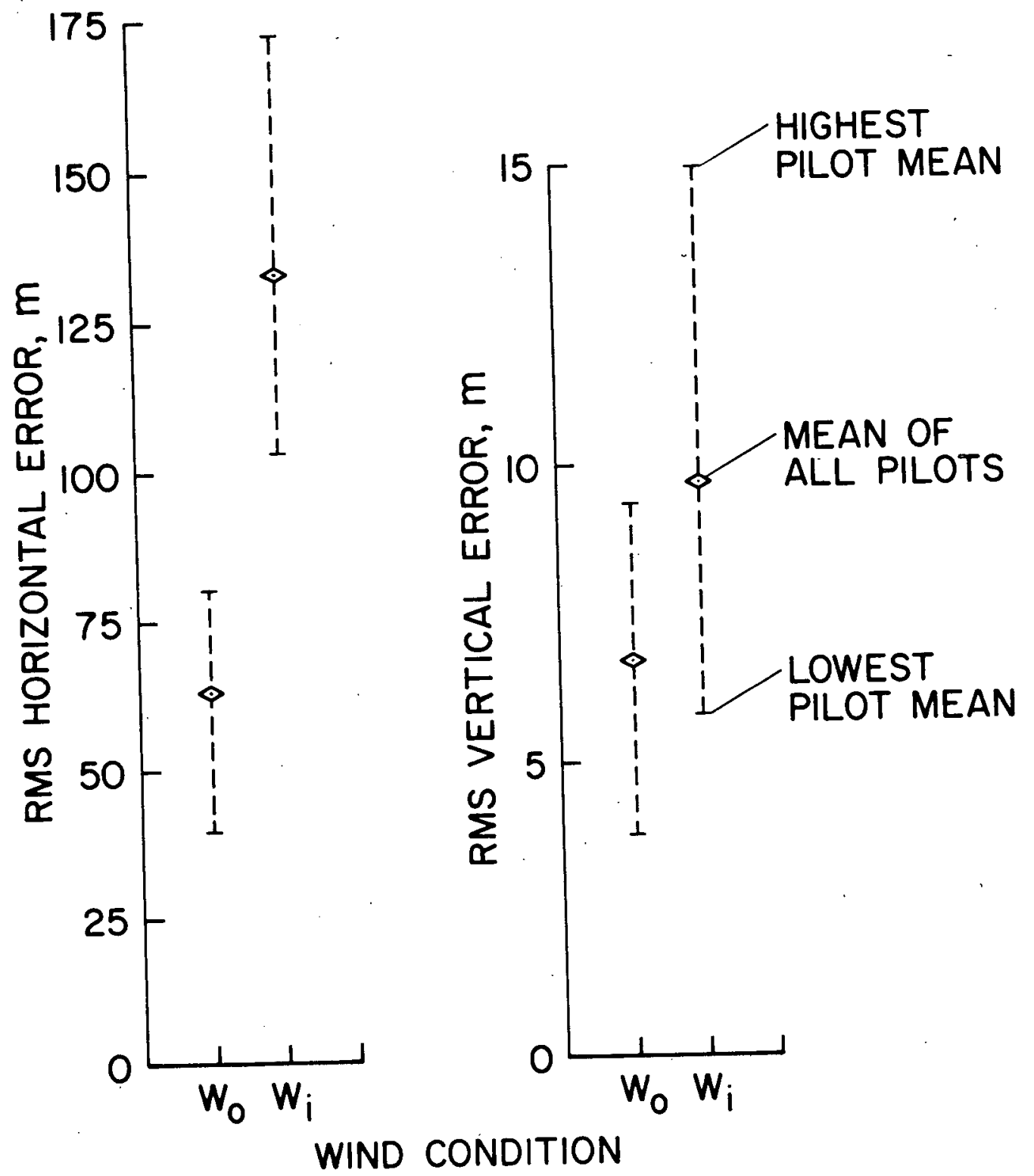

FIGURE 13. PILOT PERFORMANCE WITH AND WITHOUT WIND - SIX PILOTS 


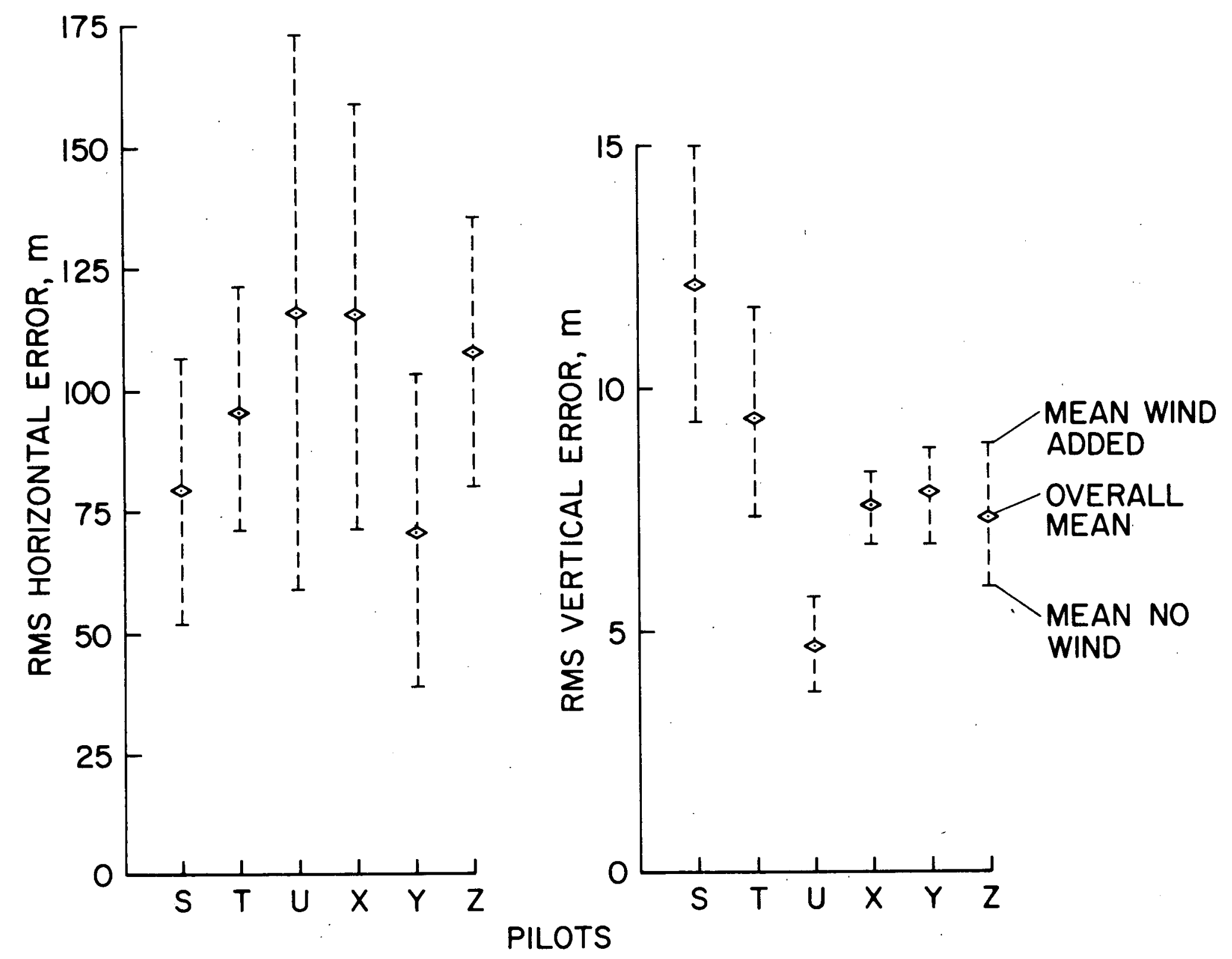

FIGURE 14. INDIVIDUAL PILOT PERFORMANCE - WITH AND WITHOUT WIND 


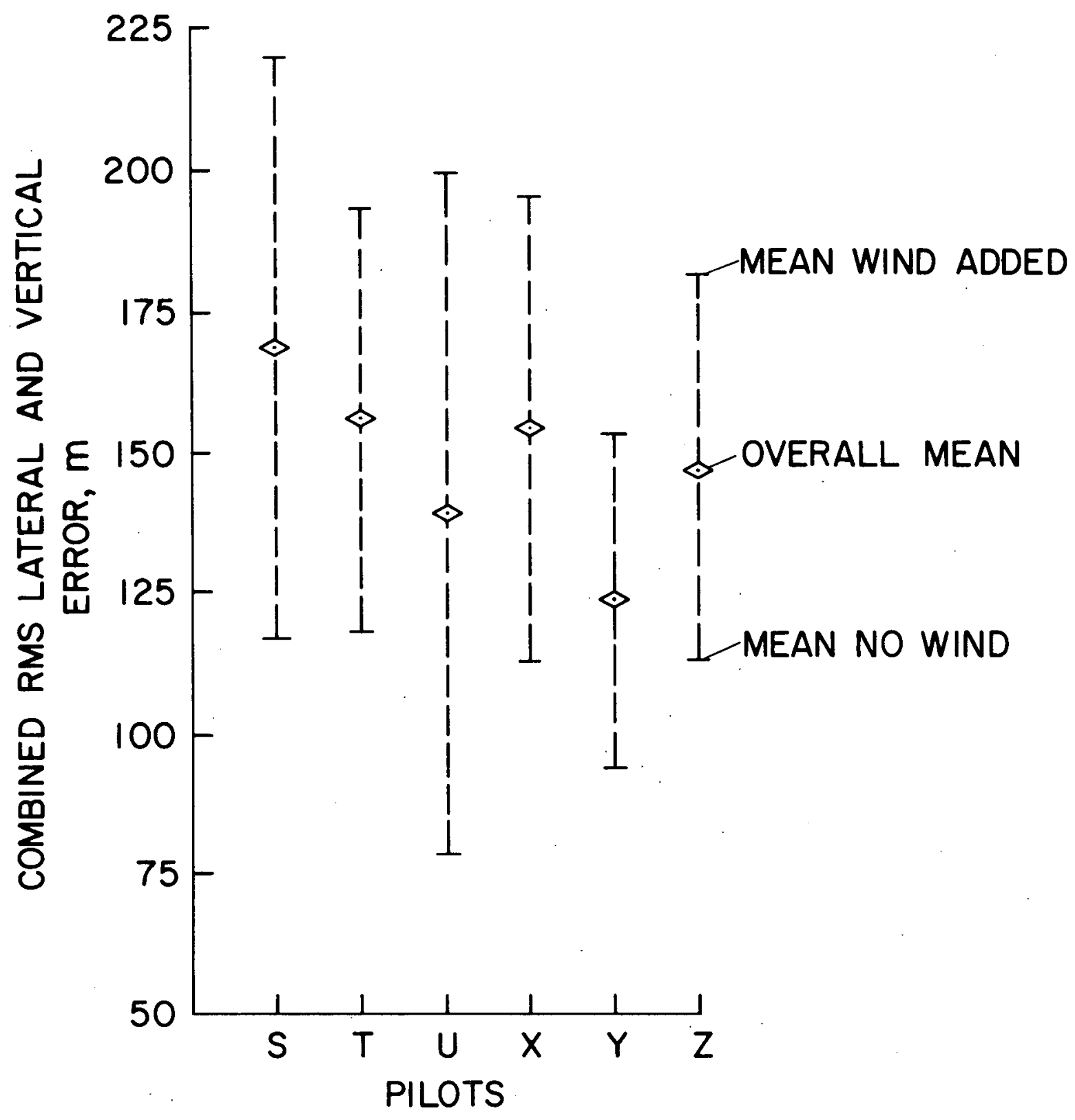

FIGURE 15. WEIGHTED LATERAL AND VERTICAL PERFORMANCE 

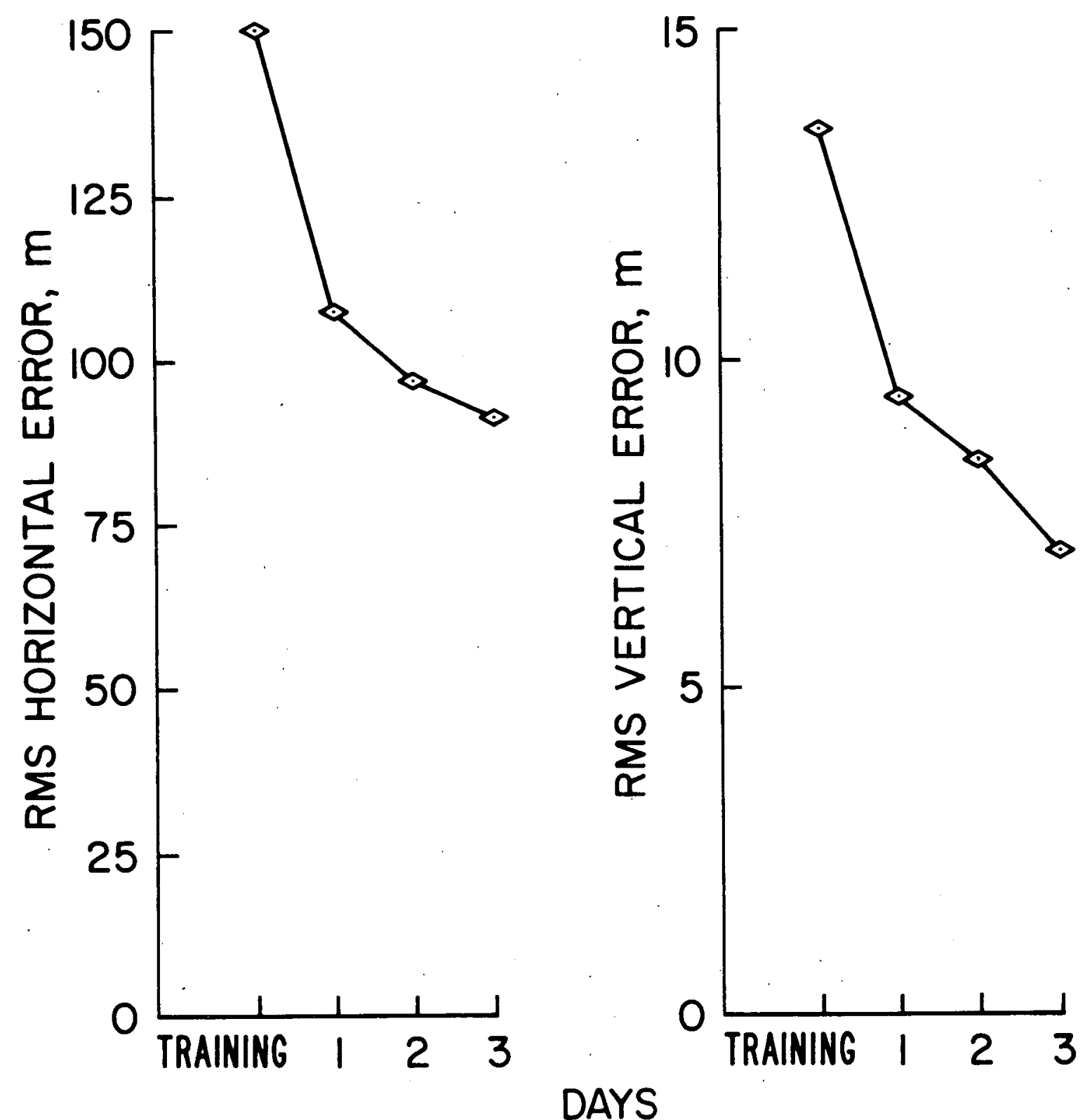

FIGURE 16. OVERALL MEAN PERFORMANCE FOR SEQUENTIAL DAYS - SIX PILOTS 